Document downloaded from:

http://hdl.handle.net/10251/150612

This paper must be cited as:

Zuluaga, C.; Martínez, A.; Fernández, J.; López-Baldó, J.; Quiles Chuliá, MD.; Rodrigo, D. (2016). Effect of high pressure processing on carotenoid and phenolic compounds, antioxidant capacity, and microbial counts of bee-pollen paste and bee-pollen-based beverage. Innovative Food Science \& Emerging Technologies. 37:10-17. https://doi.org/10.1016/j.ifset.2016.07.023

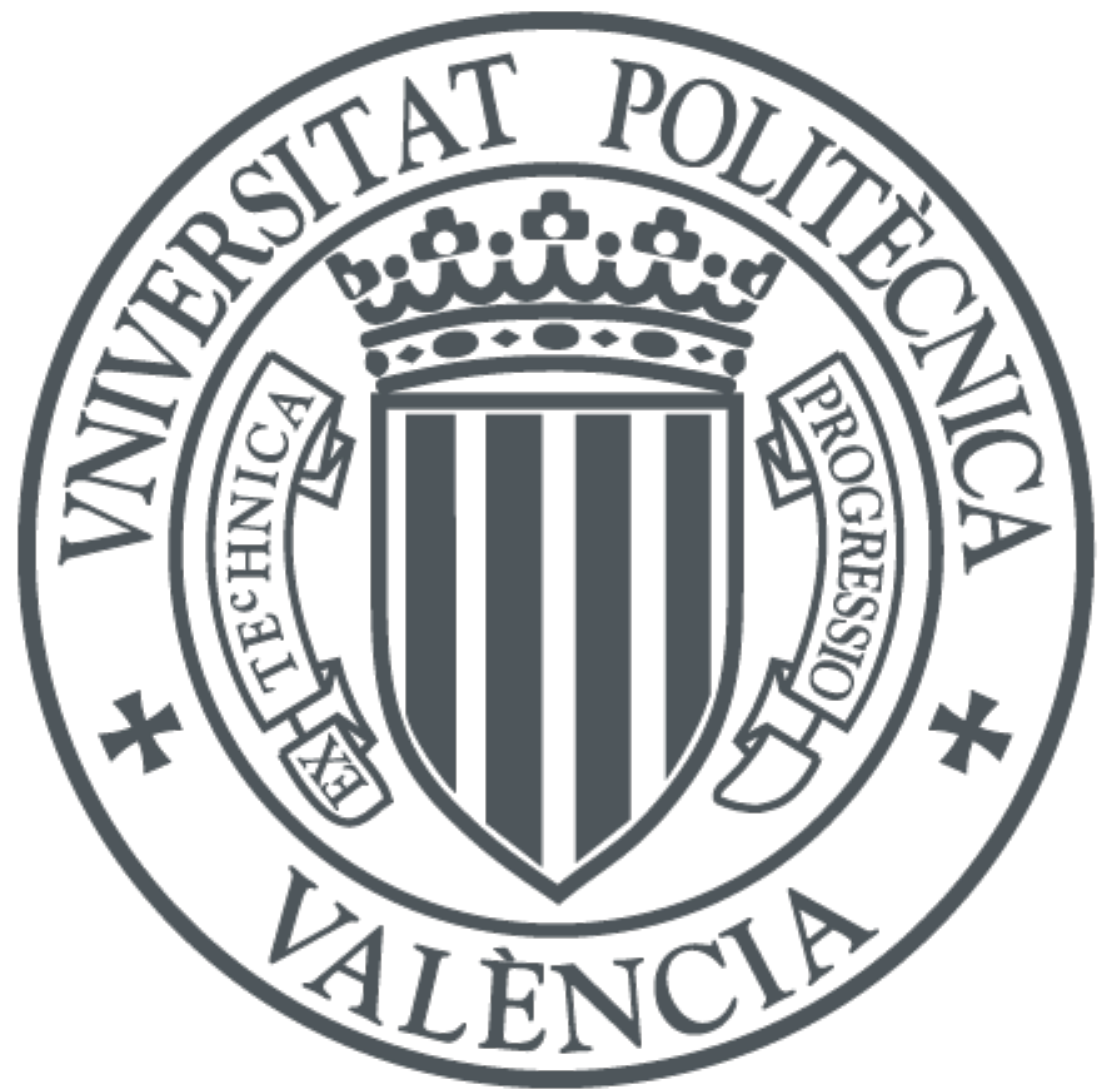

The final publication is available at

https://doi.org/10.1016/j.ifset.2016.07.023

Copyright Elsevier

Additional Information 


\title{
Effect of high pressure processing on carotenoid and phenolic compounds, antioxidant capacity, and microbial counts of bee-pollen paste and bee-pollen-based beverage
}

\author{
Zuluaga C. ${ }^{a}$, Martínez A. ${ }^{\text {b }}$, Fernández J. ${ }^{\mathrm{b}}$, López-Baldó J. ${ }^{\mathrm{c}}$, Quiles A. ${ }^{\mathrm{c}}$, Rodrigo D. ${ }^{\mathrm{b}, *}$ \\ a Institute of Food Science and Technology and Department of Chemical and Environmental Engineering, Universidad Nacional de Colombia, Carrera 30 \# 45-03, Bogotá, Colombia \\ b Instituto de Agroquímica y Tecnología de Alimentos (CSIC), Catedrático Agustín Escardino 7, 46980 Paterna, Valencia, Spain \\ c Group of Food Microstructure and Chemistry, Department of Food Technology, Universitat Politècnica de València, Camino de Vera, s/n, 46022, Valencia, Spain
}

\section{A R T I C L E I N F O}

\section{Article history:}

Received 30 March 2016

Received in revised form 25 July 2016

Accepted 25 July 2016

Available online 27 July 2016

\section{Keywords:}

Bee-pollen

Preservation

Quality

Microbiology

Carotenoids

Bioactive compounds

\begin{abstract}
A B S T R A C T
The optimal high pressure processing treatments (200-400 MPa, 5-15 min) of a pasty matrix of bee-pollen mixed with peptone water $(1.5 \mathrm{~g} / \mathrm{mL})$ and bee-pollen added to a pineapple juice-based beverage matrix $(0-10 \%(w / v))$ were studied in order to guarantee food safety and maximum retention of bioactive compounds. Salmonella and yeasts were used as target microorganisms, while total carotenoid content (TCC), total phenolic content (TPC), and antioxidant capacity (FRAP) were studied from the food quality point of view. For the pasty matrix of bee-pollen, the results showed a significant influence of pressure and time, increasing the levels of TPC, FRAP, and TCC, in comparison with a control sample. A treatment of $395 \mathrm{MPa}$ for $15 \mathrm{~min}$ was found as the optimal. For the pineapple juice-based beverage matrix, the factors pressure and bee-pollen concentration increased the levels of TPC, FRAP and TCC. Optimal conditions were found at $315 \mathrm{MPa}$ for 14.5 min with $8 \%(\mathrm{w} / \mathrm{v})$ of bee-pollen.

Industrial relevance: This investigation demonstrated the efficacy of the application of HPP on bee-pollen to inactivate microorganisms, both pathogenic and spoilage, up to 5-log 10 cycles. Additionally, a structural modification of the grain was achieved, with a consequent extractability of bioactive compounds and an increasing in the antioxidant activity, higher than $60 \%$ in comparison to fresh bee-pollen. The inclusion of bee-pollen in a fruit juice-based beverage matrix had a positive effect on the contribution of bioactive compounds that the fruit juice itself does not contain, such as carotenoids, for which bee-pollen can be considered as a natural additive that enhances the product functional characteristics.
\end{abstract}

\section{Introduction}

Increased consumer awareness of natural food products has modified current diets, encouraging consumers to demand food that not only provides the essential nutrients for life but also contains substances with potential health benefits. Moreover, and perhaps in response to consumer demands, current trends in the food preservation industry include avoiding the utilization of intense thermal treatments and chemical additives to promote foods rich in secondary metabolites that act as natural preservatives, achieving a minimum impact on the nutritional and physicochemical properties of foods.

Bee-pollen is the main source of protein for bee colonies. Worker bees transport the pollen from flowers into the hive by carrying it on their hind legs as pellets that they form with movements of their front legs, using combs, hairs, and salivary secretions (Almeida-Muradian, Pamplona, Coimbra, \& Barth, 2005). Proper hive management promotes additional pollen collection aimed at human consumption, since it can be considered as a food or food additive owing to its content of a wide range of nutrients (Human \& Nicolson, 2006). Pollen consumption and marketing have recently achieved some diffusion; however, this product went practically unrecognized as a food product for a long time, except by vegetarian or naturist consumers (Fuenmayor et al., 2014). At present there are only a few countries (e.g. Spain, China, Hungary, Argentina, and Brazil) where pollen production is economically attractive; even so, the pollen consumer market has strengthened during the last couple of decades (Campos et al., 2008). Countries such as Brazil, Argentina, Switzerland, Spain, and Mexico have established official quality standards and recognized pollen as a food product (Bogdanov, 2011).

Bee-pollen can be considered as a functional dietary supplement, especially because of its antioxidant properties (Kaškonienė, Ruočkuvienè, Kaškonas, Akuneca, \& Maruška, 2014), its micronutrient composition (Somerville \& Nicol, 2002), its fatty acid profile (Markowicz et al., 2004), and its therapeutic or disease-preventing functions (Pinto et al., 2010).

The most important bioactive substances in bee-pollen are phenolic compounds and carotenoids. Phenolic compounds are the most 
abundant secondary metabolite source in bee-pollen, responsible for the color of the grain (yellow, brown, red, purple, etc.), and its characteristic bitter taste (Bogdanov, 2011). Some phenolic compounds present in pollen are: $p$-hydroxybenzoic, $p$-coumaric, vanillic, gallic, and ferulic acid, quercetin, isorhamnetin, galangin, chrysin, and pinocembrin (LeBlanc, Davis, Boue, DeLucca, \& Deeby, 2009). Carotenoids are also important for color and for other biological functions, such as antioxidant activity, provitamin A activity, and enhancement of the immune system (Fernández-García et al., 2012). In particular, the following carotenoids have been identified in pollen: $\beta$-carotene, cryptoxanthin, $\beta$-carotene-5,6,5,6-diepoxide, zeaxanthin, antheraxanthin, violaxanthin, neoxanthin, flavoxanthin, lutein, 9/9-(Z)-lutein, and luteoxanthin (Schulte, Mäder, Kroh, Panne, \& Kneipp, 2009).

In spite of these properties, previous research suggests that the availability for humans of the beneficial components present in beepollen is limited (Cook, Awmack, Murray, \& Williams, 2003). There have been doubts about the ability of the human digestive system to break the outer layer of pollen and to absorb substances found inside. Various in vitro simulations of human digestion suggest that pollen is partially digested - between $48 \%$ and 59\% - (Franchi, Corti, \& Pompella, 1997). The outer layer is known as exine, a very strong, firm compound made of sporopollenin, which preserves the substances that are in the interior of the grain from oxidation, radiation, and chemical degradation due to UV light (Rowley \& Skvarla, 2000). Sporopollenin structure has been extensively studied: it is made primarily of carbon, hydrogen, and oxygen, with an empirical formula $\mathrm{C}_{90} \mathrm{H}_{144} \mathrm{O}_{27}$ (Atkin et al., 2011). It has also been proposed that its structure consists of a lipid copolymer of $p$-hydroxycinnamic acids (ferulic and p-coumaric acid) and fatty acids, cross-linked with ethers and esters, and some types of carotenoids, tocopherols, pro-vitamin A, and vitamin D (Thomasson et al., 2010).

Some preservation treatments (osmotic dehydration, modified atmospheres, frying, microwave, freezing, and pasteurization) cause microstructural modifications in treated foods, facilitating the liberation of compounds from the food matrix, which would contribute to increasing the fraction that is absorbed during digestion (Guardeño, Sanz, Fiszman, Quiles, \& Hernando, 2011). High pressure processing (HPP) is one of the most economically viable of what are known as nonthermal treatments (Rastogi, Raghavarao, Balasubramaniam, Niranjan, \& Knorr, 2007). The effects of HPP on the nutritional and bioactive compounds and the microstructure of food have been studied (Barba, Criado, Belda-Galbis, Esteve, \& Rodrigo, 2014; Vázquez-Gutiérrez et al., 2013), showing that this treatment causes structural changes that favor the structural compaction and extractability of bioactive compounds.

Consequently, it would be interesting to study the effect of HPP on microbial inactivation, as well as the extractability and availability of bioactive compounds of bee-pollen. The objective of this study was to assess the extraction capability and effects of HPP on bee-pollen components. Two HPP treatments, consisting of a pasty matrix of bee-pollen mixed with peptone water and, in addition, bee-pollen added to a pineapple juice-based beverage matrix, were optimized in terms of the maximum amount of bioactive compounds and the maximum reduction in the microbial load (more than $5 \log$ reductions). Such processes would make it possible to select the conditions and bee-pollen concentration with the highest bioactive compound content in order to develop new ingredients of interest for formulating special foods.

\section{Materials and methods}

\subsection{Samples}

Collected bee-pollen was provided by manufacturers from the Colombian central region known as Cundiboyacense Highland. The bee-pollen was subjected to convection drying at $60^{\circ} \mathrm{C}$ for $6 \mathrm{~h}$. The pineapple juice-based commercial beverage contained in a Tetra-Pak ${ }^{\circledR}$ carton package was selected for bee-pollen inclusion. It was purchased from a local supermarket and then stored at room temperature previous to experimental studies.

\subsection{Microorganisms}

Two microorganisms were selected to assess the effects of HPP and bee-pollen on reducing the microorganisms' concentration and growth. Salmonella typhimurium (CECT 443) and Zygosaccharomyces rouxii (CECT 1229) were obtained from lyophilized pure cultures provided by the Spanish Type Culture Collection. S. typhimurium represents a widely recognized foodborne pathogen, and $Z$. rouxii, a known spoilage yeast, mainly of sweet foods and beverages, and resistant to many of the common food preservation methods (Leandro, Sychrova, Prista, \& LoureiroDias, 2011). The stock vials containing $S$. typhimurium and $Z$. rouxii were generated following the methods described by Saucedo-Reyes, Marco-Celdrán, Pina-Pérez, Rodrigo, and Martínez-López (2009). The average cell concentrations were ca. $5.0 \times 10^{6} \mathrm{cfu} / \mathrm{mL}$ for $S$. typhimurium and ca. $5.1 \times 10^{6} \mathrm{cfu} / \mathrm{mL}$ for $Z$. rouxii. Values were established by viable plate count, using Tryptic Soy Agar (TSA; Scharlau Chemie S. A., Spain) and Potato Dextrose Agar acidified with tartaric acid (1\% (v/v)) (PDA; Scharlau Chemie S. A., Spain) for the spreading of samples.

\subsection{Sample preparation and HPP treatments}

Two studies were carried out; first, bee-pollen was moistened with peptone water as a neutral reference medium $(1.5 \mathrm{~g} / \mathrm{mL})$ and the product resulted in a bee-pollen paste. Inoculated and uninoculated paste samples were then poured into polyethylene bags and heat-sealed (MULTIVAC Thermosealer, Switzerland) before undergoing HPP treatment.

A second study was performed, considering a food matrix as a carrier of bee-pollen grains. For this purpose, different concentrations of beepollen ( 2.5 and $5 \mathrm{~g}$ ) were added to pineapple juice samples $(50 \mathrm{~mL})$ to obtain final bee-pollen concentrations of $5 \%$ and $10 \%(\mathrm{w} / \mathrm{v})$, respectively. The higher bee-pollen concentration $(10 \%(\mathrm{w} / \mathrm{v}))$ was selected taking into account the reported average $\beta$-carotene daily intake required by an average person ( $8.1 \mathrm{mg}$ ) (Souverein et al., 2015); previous assays allowed evaluation of the bee-pollen's total carotenoid content (454.05 $\pm 4.10 \mathrm{mg} \beta$-carotene $/ \mathrm{kg}$ ). A blank sample was formulated with $50 \mathrm{~mL}$ of pineapple juice. Then the inoculated and uninoculated samples were packed in polyethylene bags that were heat-sealed (MULTIVAC Thermosealer, Switzerland) before being inserted in the pressure vessel.

HPP treatments were performed in a unit with a $2.35 \mathrm{~L}$ vessel volume with a maximum operating pressure of $600 \mathrm{MPa}$ (High-Pressure Food Processor, EPSI NV, Belgium). The samples were pressurized at 200,300 , and $400 \mathrm{MPa}$, at room temperature $\left(18-22^{\circ} \mathrm{C}\right)$, for 5,10 , and $15 \mathrm{~min}$, using a compression rate of $300 \mathrm{MPa} / \mathrm{min}$ and a decompression time $<1$ min not including come-up and come-down times. All other parameters such as pressure level, pressurization time, and temperature were automatically controlled. Once the treatment had been completed, the samples were taken from the vessel, immersed in an ice-water bath and then stored under refrigeration $\left(3 \pm 1^{\circ} \mathrm{C}\right)$ until use.

\subsection{Total carotenoid content}

The total carotenoid content was measured as suggested by Hornero-Méndez and Mínguez-Mosquera (2001), with modifications. The sample $(5 \mathrm{~g}$ ) was extracted with $25 \mathrm{~mL}$ of cooled acetone using a homogenizer (IKA T25 Basic Ultra-Turrax) and vacuum filtered. This process was performed three more times. The extract was added gradually to $50 \mathrm{~mL}$ of ethyl ether in a decanting funnel. With each addition of extract, enough $\mathrm{NaCl}$ solution $(100 \mathrm{~g} / \mathrm{L})$ was added to separate the phases and transfer the pigments to the ether phase. Then the aqueous phase was removed. The ether phase was treated several times with 
anhydrous $\mathrm{Na}_{2} \mathrm{SO}_{4}(20 \mathrm{~g} / \mathrm{L})$ to remove residual water and was evaporated to dryness in a rotary evaporator (model RII; Büchi Labortechnik, Flawil, Switzerland) at a temperature below $35^{\circ} \mathrm{C}$. Finally, the pigments were collected with acetone to a volume of $100 \mathrm{~mL}$ and the absorbance was measured at $450 \mathrm{~nm}$ using a spectrophotometer (model Helios Zeta UV Visible; Thermo Fisher Scientific Inc., Cambridge, UK). A calibration curve was constructed with different concentrations of $\beta$-carotene (Sigma Aldrich, Madrid, Spain) in acetone (Panreac, Barcelona, Spain). The results were expressed as $\mathrm{mg} \beta$-carotene $/ \mathrm{kg}$ of sample.

\subsection{Total phenolic content}

The total phenolic content was determined according to the method described by (Singleton, Orthofer, \& Lamuela-Raventos, 1999), with some modifications. $10 \mathrm{~mL}$ of sample was homogenized in an UltraTurrax with $25 \mathrm{~mL}$ of ethanol $(960 \mathrm{~g} / \mathrm{kg})$. The homogenate was centrifuged $\left(27,716 \mathrm{~g}, 20 \mathrm{~min}, 4^{\circ} \mathrm{C}\right)$ and filtered. The supernatant was kept. More supernatant was extracted from the sample with $25 \mathrm{~mL}$ of ethanol $(960 \mathrm{~g} / \mathrm{kg})$ and added to the first supernatant. The total supernatant was brought up to $100 \mathrm{~mL}$ with ethanol $(960 \mathrm{~g} / \mathrm{kg})$. Then $6 \mathrm{~mL}$ of distilled water and $500 \mu \mathrm{L}$ of Folin-Ciocalteu reagent $(1: 1(\mathrm{v} / \mathrm{v}))$ were added to an aliquot of $1 \mathrm{~mL}$ of the ethanolic extract. After three minutes, $3 \mathrm{~mL}$ of sodium carbonate solution $(20 \%(w / v)$ ) (Scharlau Chemie S. A., Spain) and $1.5 \mathrm{~mL}$ of distilled water were added. The mixture was vortexed and kept at room temperature in a dark room for $1.5 \mathrm{~h}$. Absorbance was measured at $765 \mathrm{~nm}$ using a spectrophotometer (model Helios Zeta UV Visible; Thermo Fisher Scientific Inc., Cambridge, UK), and the results were expressed as mg of gallic acid equivalents (GAE)/g.

\subsection{Antioxidant activity}

The antioxidant activity was measured by a Ferric Reducing Antioxidant Power assay (FRAP). The extracts were obtained in the same way as for total phenolic content determination. Distilled water $(30 \mu \mathrm{L})$, sample $(30 \mu \mathrm{L})$, and FRAP reagent $(900 \mu \mathrm{L})$ were placed in each cuvette. The cuvettes were incubated for $30 \mathrm{~min}$ in a water bath at $37^{\circ} \mathrm{C}$ and the absorbance was measured at $595 \mathrm{~nm}$. The calibration curve was obtained using different concentrations of Trolox in ethanol $(960 \mathrm{~g} / \mathrm{kg})$. The results were expressed as $\mu \mathrm{mol}$ Trolox/g of sample.

\subsection{Microbial inactivation}

The number of colony-forming units before and after the HPP treatments for all samples with and without bee-pollen was determined using $\log _{10}(\mathrm{cfu} / \mathrm{mL}$ ). A viable plate count, using TSA (Scharlau Chemie S. A., Spain) for the sample spreading was performed for Salmonella inactivation, employing an incubation period of $48 \mathrm{~h}$ at $37^{\circ} \mathrm{C}$, meanwhile, PDA acidified with tartaric acid ( $1 \%(\mathrm{v} / \mathrm{v})$ ) (Scharlau Chemie S. A., Spain) was used for $Z$. rouxii with an incubation period of 5 days at $25{ }^{\circ} \mathrm{C}$. The counts for evaluating the inactivation of both microorganisms were performed before and after each treatment. Two aliquots were taken of each sample tested and diluted with buffered peptone water (Scharlau Chemie S. A, Spain). Then, two plates were spread for each one of the aliquots, thus, each count was obtained from four plates.

\subsection{Confocal laser scanning microscopy (CLSM)}

A Nikon confocal microscope C1 unit fitted on a Nikon Eclipse E800 microscope (Nikon, Tokyo, Japan) was used. The autofluorescence of the samples was observed using the Ar laser line without any dye. A $60 \times / 1.40 \mathrm{NA} / \mathrm{Oil} / \mathrm{Plan}$ Apo VC Nikon objective lens was used. The images were obtained and stored at a $1024 \times 1024$-pixel resolution using the microscope software (EZ-C1 v.3.40, Nikon, Tokyo, Japan).

\subsection{Experimental design and statistical analysis}

Response surface methodology (RSM) was used as a tool to optimize the preservation process and to investigate the simultaneous effects of pressure, time, and bee-pollen concentration on total phenolic content, total carotenoid content, antioxidant activity, and microbiological inactivation of the prepared samples.

For studies on reference medium, a face-centered central composite design was used with three levels (maximum, minimum, and central) of two independent factors, pressure (from 200 to $400 \mathrm{MPa}$ ) and time (from 5 to $15 \mathrm{~min}$ ), being in total 10 combinations (Table 1 ). The levels selection was done according to HPP operating conditions. In addition, for the pineapple juice-based beverage matrix a face-centered central composite design was also used with three levels (maximum, minimum, and central) and three independent factors, pressure (from 200 to $400 \mathrm{MPa}$ ), time (from 5 to $15 \mathrm{~min}$ ), and bee-pollen concentration (from 0 to $10 \%(\mathrm{w} / \mathrm{v})$ ), leading to 16 combinations (Table 2 ).

The central point of the 3 variables was replicated 2 times in order to assure the reproducibility and stability of the results. Each experimental design was performed twice, thus, two blocks of experiments for each treatment were obtained (Barba et al., 2014).

All the experiments were randomized, while the samples were treated in duplicate and analyzed in triplicate. The experimental design and the data analysis were performed using the Statgraphics $\AA$ Centurion XV software (Statpoint Technologies, Inc., USA). A quadratic model was obtained with regression coefficients associated with the linear, quadratic and interaction effects, and their significance was determined by a $t$-test through the $p$-value generated (Barba et al., 2014). An ANOVA test was performed to find significant differences $(p<0.05)$ in TCC, TPC, and FRAP results between treatments.

\section{Results and discussion}

\subsection{Effect of HPP on TCC, TPC, FRAP, and microbial counts of bee-pollen paste}

The effects of HPP treatments on TCC, TPC, and FRAP, and on microbial inactivation in bee-pollen in the reference media are shown in Table 3. Polyphenol content in the untreated bee-pollen paste is comparable to those from the Sonoran Desert (USA) (15.91-34.85 mg GAE/g) (LeBlanc et al., 2009) or India (18.29 mg GAE/g) (Ketkar et al., 2014), and higher than reported from Portugal (10.50-16.80 mg GAE/g) (Morais, Moreira, Feás, \& Estevinho, 2011), or Spain (8.50-14.60 mg GAE/g) (SerraBonvehí, Soliva-Torrentó, \& Centelles-Lorente, 2001). In addition, carotenoid contents comparable to those of the untreated bee-pollen were found by Barajas, Cortes-Rodriguez, and Rodríguez-Sandoval (2012) and Almeida-Muradian et al. (2005) of up to 770 and $451 \mathrm{mg} \beta$ carotene $/ \mathrm{kg}$ for Colombian and Brazilian bee-pollen, respectively. For FRAP antioxidant activity, (Ulusoy \& Kolayli, 2013) reported levels ranging between 11.7 and $105.6 \mu \mathrm{mol}$ Trolox/g for Turkish bee-pollen.

\section{Table 1}

Experimental design matrix for studies carried out in reference medium.

\begin{tabular}{lll}
\hline Run & $\begin{array}{l}\text { Pressure }(\mathrm{MPa}) \\
\left(\mathrm{X}_{1}\right)\end{array}$ & $\begin{array}{l}\text { Time }(\mathrm{min}) \\
\left(\mathrm{X}_{2}\right)\end{array}$ \\
\hline 1 & 400 & 10 \\
2 & 200 & 15 \\
3 & 300 & 15 \\
4 & 400 & 15 \\
5 & 400 & 5 \\
6 & 300 & 5 \\
$7^{\mathrm{a}}$ & 300 & 10 \\
$8^{\mathrm{a}}$ & 300 & 10 \\
9 & 200 & 5 \\
10 & 200 & 10 \\
\hline
\end{tabular}

\footnotetext{
a Central point
} 
Table 2

Experimental design matrix for studies carried out in food matrix.

\begin{tabular}{llll}
\hline Run & $\begin{array}{l}\text { Pressure }(\mathrm{MPa}) \\
\left(\mathrm{X}_{1}\right)\end{array}$ & $\begin{array}{l}\text { Time }(\mathrm{min}) \\
\left(\mathrm{X}_{2}\right)\end{array}$ & $\begin{array}{l}\text { Bee-pollen }(\%(\mathrm{w} / \mathrm{v})) \\
\left(\mathrm{X}_{3}\right)\end{array}$ \\
\hline 1 & 400 & 10 & 5 \\
2 & 200 & 15 & 0 \\
3 & 300 & 10 & 0 \\
4 & 300 & 15 & 5 \\
5 & 400 & 15 & 0 \\
6 & 400 & 5 & 0 \\
7 & 300 & 5 & 5 \\
8 & 200 & 15 & 10 \\
$9^{\mathrm{a}}$ & 300 & 10 & 5 \\
10 & 400 & 5 & 10 \\
11 & 400 & 15 & 10 \\
$12^{\mathrm{a}}$ & 300 & 10 & 5 \\
13 & 200 & 5 & 0 \\
14 & 200 & 5 & 10 \\
15 & 300 & 10 & 10 \\
16 & 200 & 10 & 5 \\
\hline
\end{tabular}

a Central point.

As can be seen in Table 3, both pressure and time had a positive effect by increasing the extraction of TPC and TCC, as well as on the FRAP antioxidant activity of the treated bee-pollen paste, compared with the control sample. In the case of TPC, the extractability was enhanced at the maximum pressure and time set in the experimental design (400 MPa, $15 \mathrm{~min}$ ). The increase in the extracted compounds was close to $36 \%$, in comparison with the control.

With regard to TCC and FRAP antioxidant activity, it was observed that there were no significant differences $(p>0.05)$ between results for TCC extraction and FRAP when pressures of 300 or $400 \mathrm{MPa}$ were employed. For the time factor, a trend toward having higher carotenoid extraction and antioxidant capacity with longer times was observed. The best results were obtained at $400 \mathrm{MPa}$ for a time of $15 \mathrm{~min}$, at which levels of TCC and FRAP antioxidant activity were higher $(41 \%$ and $26 \%$, respectively) than those of the control sample.

Microbial inactivation showed that the most effective treatments were only able to inactivate $3 \log$ cycles at most. In the case of Salmonella, higher inactivation was obtained after 15 min of treatment time, regardless of the pressure exerted. For $Z$. rouxii, higher values were obtained at $400 \mathrm{MPa}$, with a treatment of $15 \mathrm{~min}$. The fact that higher cycles of inactivation could not be achieved may be due to reduced water content in the samples, and the pressure may not have been transmitted uniformly throughout the HPP-treated sample.

\subsection{Processing parameter optimization}

The best processing conditions for treating bee-pollen paste using peptone water as aqueous medium were studied by RSM. Eqs. (1) to (3) show the response function for the factors studied: TCC, TPC, and
FRAP, while the effect of bee-pollen concentration and HPP conditions on the mentioned factors is shown in Fig. 1.

$$
\mathrm{TCC}=632.99+121.33 * \mathrm{P}+56.05 * \mathrm{t}-96.90 * \mathrm{P}^{2} \quad \text { Corrected } \mathrm{R}^{2}=0.85
$$

$\mathrm{TPC}=27.96+2.76 * \mathrm{P}+6.37 * \mathrm{t} \quad$ Corrected $\mathrm{R}^{2}=0.71$

$$
\text { FRAP }=112.66+18.5 * \mathrm{P}+20.3 * \mathrm{t} \quad \text { Corrected } \mathrm{R}^{2}=0.78
$$

It can be seen that interactions and quadratic effects have a reduced effect in comparison with linear effects. A multilinear analysis of response surface design was employed to optimize HPP conditions (pressure and time) to maximize total carotenoids, total phenolic compounds, and antioxidant capacity, and also inactivate 3 log cycles of Salmonella and $Z$. rouxii. The results obtained showed that $395 \mathrm{MPa}$ applied for 15 min were the conditions that optimized treatment with an overall desirability of 0.936 . The response values predicted under this optimization were $781.31 \mathrm{mg} \beta$-carotene $/ \mathrm{kg}$ for TCC, $67.38 \mathrm{mg} \mathrm{GAE} / \mathrm{g}$ for TPC, and $496.9 \mu \mathrm{mol}$ Trolox/g for FRAP.

\subsection{Effect of HPP on TCC, TPC, FRAP, and microbial counts in a bee pollen food matrix-based beverage}

Effects of HPP treatments with and without bee-pollen on TCC, TPC, FRAP, and microbial inactivation in the pineapple juice-based beverage are shown in Table 4. With regard to total carotenoid content, untreated sample in the absence of bee-pollen had an undetectable value, while untreated samples supplemented with 5 and $10 \%$ of bee-pollen had average contents of 43.19 and $54.10 \mathrm{mg} \beta$-carotene $/ \mathrm{kg}$, respectively. According to those results, it is clear that all the carotenoids come from the added bee-pollen. As can be seen in Table 4, pressure and time favored the extraction of carotenoids, with higher values for the longer periods of treatment time and higher pressure levels. With a beepollen addition of $5 \%$, TCC increased to values up to $80.14 \mathrm{mg} \beta$ carotene $/ \mathrm{kg}$, meanwhile with an addition of $10 \%$, TCC increased up to $86.60 \mathrm{mg} \beta$-carotene $/ \mathrm{kg}$. Consequently, it appears that the HPP treatment favored the extraction of components from the interior of the pollen grain, increasing the TCC in the dispersion media in comparison with untreated samples by up to $60 \%$ and $86 \%$ for bee-pollen addition of $5 \%$ and $10 \%$, respectively.

A three-way ANOVA showed that pressure, time, and bee-pollen concentration had a significant influence on TCC $(p<0.05)$. The maximum content achieved was $86.60 \mathrm{mg} \beta$-carotene $/ \mathrm{kg}$ with the highest treatment tested (400 MPa, $15 \mathrm{~min}, 10 \%(\mathrm{w} / \mathrm{v}$ ) bee-pollen). In this case, it is suggested that HPP produces a breaking of the exine layer, favoring the release of compounds bound to the external membrane. In view of the results obtained, HPP can be considered as an efficient

Table 3

\begin{tabular}{|c|c|c|c|c|c|c|}
\hline \multirow[t]{2}{*}{ Pressure MPa } & \multirow[t]{2}{*}{ Time (min) } & \multirow[t]{2}{*}{ TPC (mg GAE/g) } & \multirow[t]{2}{*}{ TCC (mg $\beta$-carotene $/ \mathrm{kg}$ ) } & \multirow[t]{2}{*}{ FRAP ( $\mu$ mol Trolox/g) } & \multirow{2}{*}{$\begin{array}{l}\text { Salmonella } \\
\log _{10} \mathrm{~S}\end{array}$} & \multirow{2}{*}{$\frac{\text { Yeasts }}{\log _{10} \mathrm{~S}}$} \\
\hline & & & & & & \\
\hline 0 & 0 & $24.83 \pm 3.68$ & $552.27 \pm 0.91$ & $100.6 \pm 11.2$ & 0 & 0 \\
\hline 200 & 5 & $24.79 \pm 3.30$ & $597.11 \pm 2.73$ & $105.3 \pm 19.5$ & $1.65 \pm 0.03$ & $0.65 \pm 0.05$ \\
\hline 200 & 10 & $27.43 \pm 4.07$ & $631.29 \pm 0.20$ & $105.7 \pm 29.5$ & $1.83 \pm 0.01$ & $0.67 \pm 0.08$ \\
\hline 200 & 15 & $31.47 \pm 2.21$ & $655.18 \pm 4.02$ & $112.7 \pm 13.1$ & $3.93 \pm 0.04$ & $1.36 \pm 0.03$ \\
\hline 300 & 5 & $25.33 \pm 3.21$ & $720.75 \pm 0.93$ & $110.4 \pm 11.0$ & $2.87 \pm 0.02$ & $0.71 \pm 0.12$ \\
\hline 300 & 10 & $26.66 \pm 3.08^{\mathrm{a}}$ & $723.65 \pm 2.90^{\mathrm{a}}$ & $115.5 \pm 15.8^{\mathrm{a}}$ & $3.41 \pm 0.12^{\mathrm{a}}$ & $2.06 \pm 0.05^{a}$ \\
\hline 300 & 15 & $32.59 \pm 4.43$ & $770.86 \pm 5.60$ & $122.3 \pm 15.4$ & $3.73 \pm 0.26$ & $2.09 \pm 0.24$ \\
\hline 400 & 5 & $28.52 \pm 0.95$ & $718.07 \pm 2.28$ & $110.4 \pm 11.1$ & $2.49 \pm 0.10$ & $2.10 \pm 0.05$ \\
\hline 400 & 10 & $29.76 \pm 1.62$ & $751.47 \pm 9.51$ & $117.5 \pm 16.0$ & $3.29 \pm 0.02$ & $2.31 \pm 0.04$ \\
\hline 400 & 15 & $33.69 \pm 1.37$ & $778.03 \pm 1.16$ & $126.5 \pm 11.1$ & $3.41 \pm 0.06$ & $3.69 \pm 0.01$ \\
\hline
\end{tabular}

Effect of HPP on total phenolic content, total carotenoid content, and antioxidant capacity (FRAP), and microbial load of the bee-pollen paste.

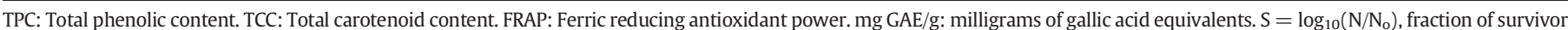
microorganisms.

a Average of central point. 


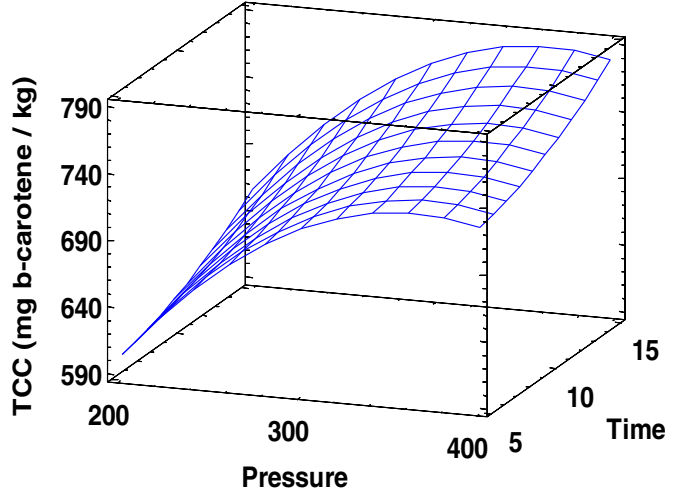

(a)

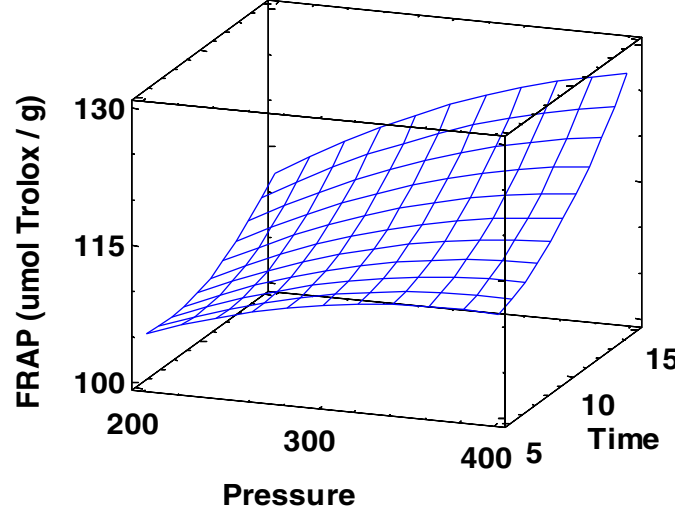

(b)

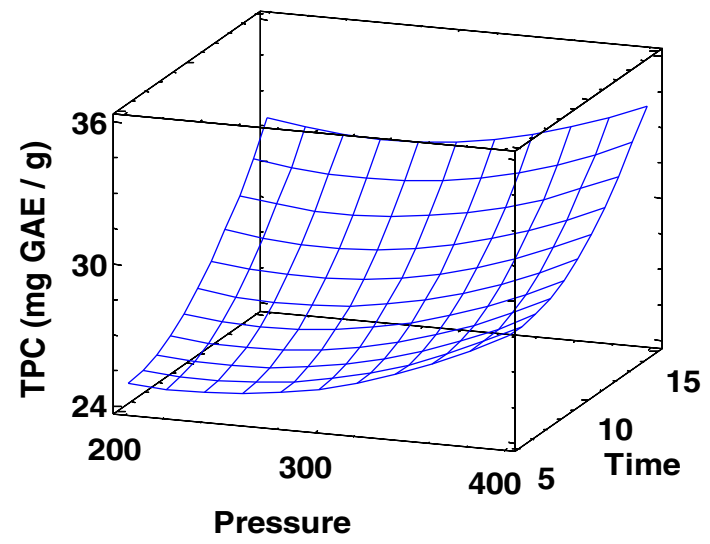

(c)

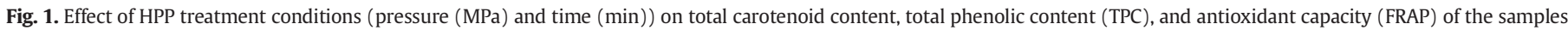
analyzed.

treatment to increase the availability of bioactive compounds in beepollen. In other processes, (e.g. drying), a reduction in TCC has been found, as carotenes are highly sensitive to temperature. Barajas et al.
(2012) found that drying pollen at $45^{\circ} \mathrm{C}$ induces carotene losses of $22 \%$ to $33 \%$. Those results are interesting because, to the best of our knowledge, this is the first time that the effect of HPP on bee-pollen

Table 4

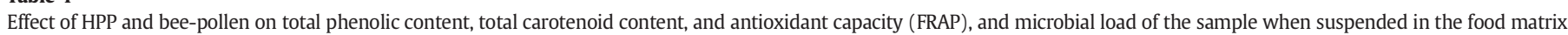

\begin{tabular}{|c|c|c|c|c|c|c|c|}
\hline \multirow[t]{2}{*}{ Pressure MPa } & \multirow[t]{2}{*}{ Time (min) } & \multirow[t]{2}{*}{ Bee-pollen \% (w/v) } & \multirow[t]{2}{*}{ TPC (mg GAE/g) } & \multirow[t]{2}{*}{ TCC (mg $\beta$-carotene $/ \mathrm{kg}$ ) } & \multirow[t]{2}{*}{ FRAP $(\mu \mathrm{mol}$ Trolox/g) } & \multirow{2}{*}{$\frac{\text { Salmonella }}{\log _{10} \mathrm{~S}}$} & \multirow{2}{*}{$\frac{\text { Yeasts }}{\log _{10} \mathrm{~S}}$} \\
\hline & & & & & & & \\
\hline 0 & 0 & 0 & $7.01 \pm 0.36$ & ND & $40.50 \pm 5.00$ & 0 & 0 \\
\hline 0 & 0 & 5 & $11.23 \pm 0.57$ & $43.19 \pm 1.19$ & $57.70 \pm 2.30$ & 0 & 0 \\
\hline 0 & 0 & 10 & $13.82 \pm 0.39$ & $54.10 \pm 0.13$ & $58.30 \pm 4.30$ & 0 & 0 \\
\hline 200 & 5 & 0 & $6.88 \pm 0.79$ & ND & $63.20 \pm 1.70$ & $1.27 \pm 0.09$ & $1.10 \pm 0.01$ \\
\hline 200 & 5 & 10 & $17.55 \pm 0.83$ & $55.06 \pm 0.36$ & $122.60 \pm 4.00$ & $2.72 \pm 0.18$ & $1.06 \pm 0.13$ \\
\hline 200 & 10 & 5 & $8.76 \pm 0.38$ & $51.65 \pm 0.03$ & $65.50 \pm 7.10$ & $2.42 \pm 0.02$ & $2.25 \pm 0.27$ \\
\hline 200 & 15 & 0 & $4.74 \pm 0.46$ & ND & $59.30 \pm 2.40$ & $5.50 \pm 0.13$ & $2.33 \pm 0.03$ \\
\hline 200 & 15 & 10 & $14.57 \pm 0.32$ & $70.47 \pm 0.78$ & $117.60 \pm 6.10$ & $5.66 \pm 0.02$ & $4.53 \pm 0.08$ \\
\hline 300 & 5 & 5 & $9.22 \pm 0.33$ & $56.33 \pm 0.53$ & $94.10 \pm 2.30$ & $5.33 \pm 0.51$ & $4.13 \pm 0.04$ \\
\hline 300 & 10 & 0 & $4.00 \pm 0.29$ & ND & $83.00 \pm 4.20$ & $5.16 \pm 0.09$ & $5.00 \pm 0.03$ \\
\hline 300 & 10 & 5 & $12.90 \pm 0.56^{\mathrm{a}}$ & $66.14 \pm 0.18^{\mathrm{a}}$ & $91.50 \pm 5.60^{\mathrm{a}}$ & $5.14 \pm 0.11^{\mathrm{a}}$ & $5.07 \pm 0.02^{a}$ \\
\hline 300 & 10 & 10 & $15.49 \pm 1.84$ & $74.05 \pm 0.79$ & $123.80 \pm 6.00$ & - & $5.08 \pm 0.07$ \\
\hline 300 & 15 & 5 & $11.89 \pm 0.29$ & $78.85 \pm 0.38$ & $105.10 \pm 7.30$ & $>6^{+}$ & $4.76 \pm 0.14$ \\
\hline 400 & 5 & 0 & $4.27 \pm 0.34$ & ND & $62.90 \pm 8.40$ & $5.71 \pm 0.05$ & $>6^{+}$ \\
\hline 400 & 5 & 10 & $16.65 \pm 1.88$ & $67.43 \pm 0.21$ & $129.70 \pm 3.60$ & $5.87 \pm 0.11$ & $>6^{+}$ \\
\hline 400 & 10 & 5 & $19.05 \pm 0.06$ & $80.14 \pm 0.24$ & $98.00 \pm 0.90$ & $5.52 \pm 0.15$ & $>6^{+}$ \\
\hline 400 & 15 & 0 & $3.97 \pm 0.20$ & ND & $93.30 \pm 3.40$ & $>6^{+}$ & $>6^{+}$ \\
\hline 400 & 15 & 10 & $20.34 \pm 1.08$ & $86.60 \pm 0.35$ & $140.30 \pm 4.90$ & $5.40 \pm 0.04$ & $>6^{+}$ \\
\hline
\end{tabular}

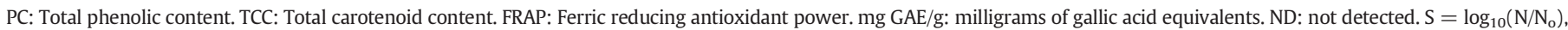
fraction of survivor microorganisms.

a Average of central point. N/A.

+ More than $6 \log$ reductions. 
has been reported, and this opens the door to better use of this very nutrient foodstuff.

Several reports have been made with regard to other plant product matrices, studying the effect of HPP in orange, lemon, and carrot juice (Butz et al., 2003), and carrot and broccoli (McInerney, Seccafien, Stewart, \& Bird, 2007). Those authors found no statistically significant differences $(p>0.05)$ in carotenoid extraction between the HPPtreated samples and the controls. In our study, higher values for TCC were found in treated samples than in untreated; this could indicate that a large amount of carotenoids is bound to the external membrane of the bee-pollen, which was successfully extracted when high pressures were applied, thus achieving a structural modification of the grain. It would appear, therefore, that the effects of HPP on carotenoid extraction are closely related to the plant material to which this technology is applied.

TPC was determined in the untreated samples and immediately after applying HPP in order to determine the effect of processing on this group of bioactive compounds when bee-pollen was added at different concentrations. The concentration of TPC in unprocessed samples without bee-pollen was in average $7.01 \mathrm{mg} \mathrm{GAE} / \mathrm{g}$. In the presence of $5 \%$ and $10 \%(\mathrm{w} / \mathrm{v}$ ) of bee-pollen it was 11.23 and $13.82 \mathrm{mg} \mathrm{GAE} / \mathrm{g}$, respectively. Thus the addition of bee-pollen increased TPC values significantly $(p<0.05)$.

In view of the results obtained (Table 4), only the bee-pollen concentration had a significant influence $(p<0.05)$, increasing the TPC availability in the treated samples. These results are in agreement with those published by Barba, Esteve, and Frigola (2010), who reported that phenolic compounds did not show lower levels than the control when HPP was applied to vegetable beverages. Moreover, TPC even increased by up to $69 \%$ after HPP at $400 \mathrm{MPa}$ for $10 \mathrm{~min}$ with $5 \%(\mathrm{w} / \mathrm{v})$ of bee-pollen. This increase in TPC may be due to the result of a breaking down of the exine wall following HPP, partly consisting of phenolic compounds, which are available after processing. These results also agree with those found in carrot and spinach (Jung, Lee, Kim, \& Ahn, 2013), and strawberry and blackberry purées (Patras, Brunton, Da Pieve, \& Butler, 2009), where total phenolics extraction increased after HPP.

In the present research, total antioxidant activity of samples measured with the FRAP method was determined before and immediately after applying HPP. The addition of bee-pollen increased the FRAP levels significantly $(p<0.05)$ in pressurized samples. The pressure and beepollen concentration had a significant effect on antioxidant activity in HPP-treated samples, reaching values of $140.30 \pm 4.90 \mu \mathrm{mol}$ Trolox $/ \mathrm{g}$ with the highest treatment tested (400 MPa, $15 \mathrm{~min}, 10 \%(\mathrm{w} / \mathrm{v})$ beepollen). This can be attributed to the extraction of carotenoids and polyphenols, responsible for antioxidant capacity in bee-pollen (Carpes,
Begnini, Alencar, \& Masson, 2007). Significant correlations $(p<0.05)$ were found between FRAP and TPC $(R=0.698)$, and between FRAP and TCC $(R=0.713)$.

Fig. 2 shows some confocal images of untreated and treated beepollen grains. The structural modification of the bee-pollen and the loss of the typical shape of the grain can be observed. Pollen autofluorescence came mainly from the exine wall, while it is reported that the apertures do not fluoresce (Castro et al., 2010). This fluorescence is probably due to carotenoids and phenols present in the exine, as described in other studies (Roshchina, Melnikova, \& Kovaleva, 2010). The intensity of autofluorescence was heterogeneous, some grains being brighter than others. This may show that liberation of compounds previously found in the interior of the grain was achieved, and this could also explain the increase in the reported values of bioactive compounds and antioxidant activity.

Finally, the potential of HPP as a preservation method was evaluated. Salmonella and $Z$. rouxii were selected to establish the effect of HPP on microorganism survival. In the case of Salmonella, pressure and time had a significant influence $(p<0.05)$ on inactivation. The microbial inactivation was higher when treatment time was increased (Table 4). In addition, pressures higher than $400 \mathrm{MPa}$ or times higher than $15 \mathrm{~min}$ were always able to inactivate at least $5 \log$ cycles, the standard proposed for any processing strategy intended to pasteurize and guarantee the safety of fruit juices and similar products (CFR, 2012). In the case of $Z$. rouxii, only pressure had a significant influence $(p<0.05)$. A clear trend of yeast inactivation is observed when pressure increases: at $200 \mathrm{MPa}$ the maximum inactivation achieved was $4 \log$ cycles, at $300 \mathrm{MPa}$ almost $5 \log$ cycles was achieved, and while at $400 \mathrm{MPa}$ inactivation was higher than 5 log cycles. Based on results found, beepollen might have some anti-microbial effect on treatments performed at low pressures, close to $200 \mathrm{MPa}$. At this pressure, a high microorganism concentration remained unaltered after HHP treatment, and the anti-microbial activity of bee-pollen could have some influence on the reduction of sensitive population of microorganisms. On the contrary, in HHP treatments over $300 \mathrm{MPa}$, pressure seems to be the dominant factor for the reduction on the microbial load, killing the sensitive population of microorganisms, and the anti-microbial activity of bee-pollen would not be made evident.

\subsection{Processing parameter optimization based on their effect on the safety and quality of the formulated matrix}

The best processing conditions for treating a pineapple juice-based beverage when HPP is combined with the addition of bee-pollen were studied by RSM. Eqs. (4) to (6) show the response function for the factors studied: TCC, TPC, and FRAP, while the effect of a pineapple juice-

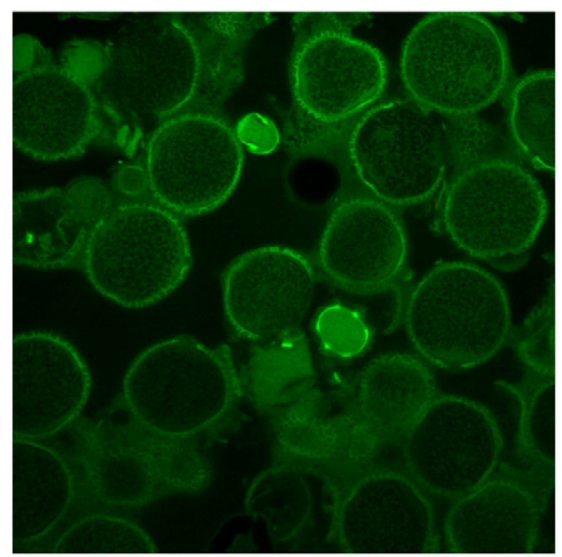

(a)

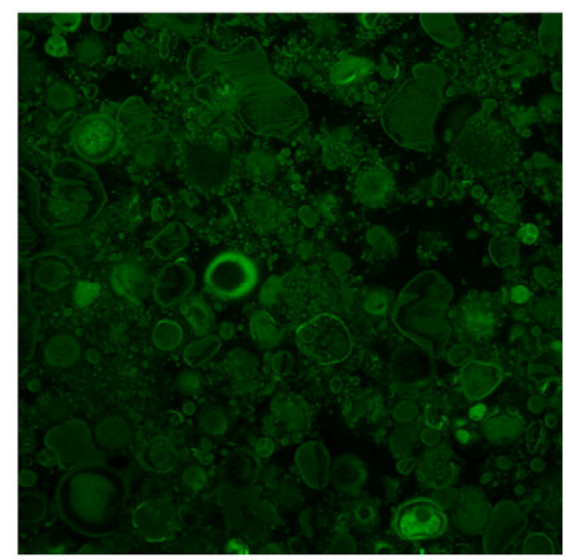

(b)

Fig. 2. Confocal images $(60 \times)$ of bee-pollen untreated (a) and treated at found optimal conditions (b). 
(a)

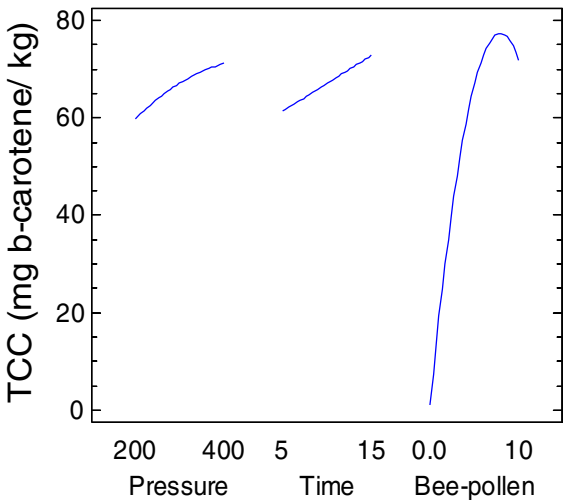

(b)

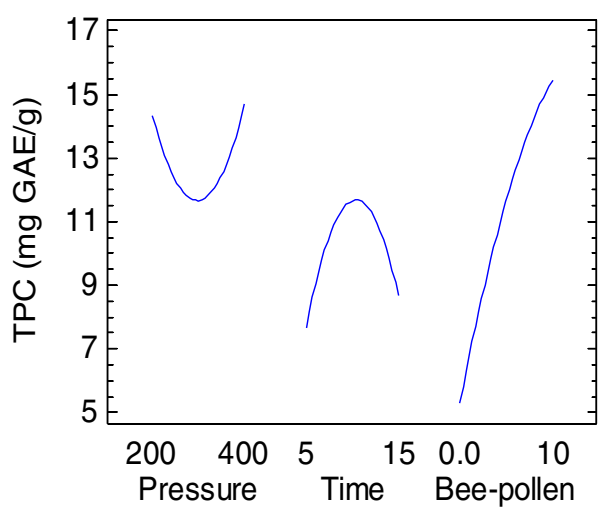

(c)

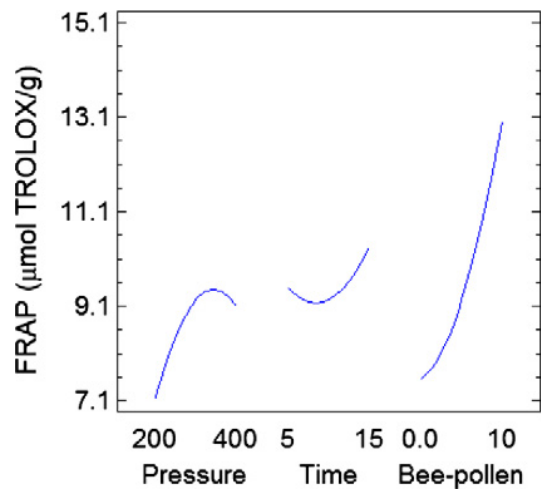

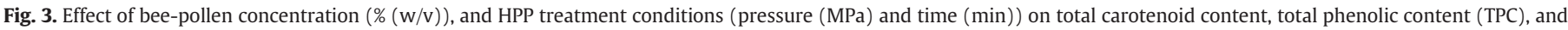
antioxidant capacity (FRAP) of the samples analyzed.

based beverage and HPP conditions on the mentioned factors is shown in Fig. 3.

$\mathrm{TCC}=67.04+11.40 * \mathrm{P}+11.42 * \mathrm{t}+70.72 * \mathrm{BP} \quad$ Corrected $\mathrm{R}^{2}=0.96$

$$
\begin{aligned}
\mathrm{TPC}= & 11.67+10.14 * \mathrm{BP} \quad \text { Corrected } \mathrm{R}^{2}=0.78 \\
\mathrm{FRAP}= & 9.23+1.92 * \mathrm{P}+5.45 * \mathrm{BP}-2.21 * \mathrm{P}^{2} \\
& +1.25 * \mathrm{Pt}+2.12 * \mathrm{BP} \quad \text { Corrected } \mathrm{R}^{2}=0.92
\end{aligned}
$$

In view of the results obtained, the time factor has less effect on the extraction of bioactive compounds than pressure and bee-pollen concentration. A multilinear analysis of response surface was employed to optimize HPP conditions (pressure and time) and the bee-pollen concentration to reach maximum values for TCC, TPC, FRAP, and microorganism inactivation. The results obtained showed that a bee-pollen concentration of $8 \%(\mathrm{w} / \mathrm{v})$ and $315 \mathrm{MPa}$ applied for $14.5 \mathrm{~min}$ were the conditions that optimized treatment with an overall desirability of 0.961 . The response values predicted under this optimization were

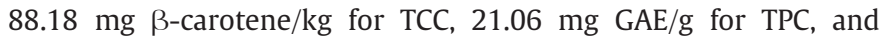
$142.70 \mu \mathrm{mol}$ Trolox/g for FRAP. Therefore, the addition of bee-pollen to a fruit juice-based beverage, considered as a model, allows an increase in the bioactive content of the product.

\section{Conclusions}

The studies of the pasty matrix of bee-pollen and the bee-pollen added to a pineapple juice-based beverage matrix both showed a significant increase in bioactive components when high pressure processing (HPP) was employed, in comparison with raw bee-pollen. In the bee-pollen paste, the HPP treatment improved the extractability of some bioactive compounds contained inside the bee-pollen grain, such as carotenoids and phenolics, as it favors their diffusion from the cell. Therefore, the availability of these compounds could be favored. Results also showed an increase in bioactive compounds and antioxidant capacity, in particular when pressure and time close to $400 \mathrm{MPa}$ and $15 \mathrm{~min}$ were applied. However, microbial inactivation of Salmonella and $Z$. rouxii achieved levels under three logarithmic reductions, which may be an indicator of a non-uniform pressure treatment, given the low water content of the samples, and may also be due to the fact that bee-pollen could provide a protective effect. A similar result was obtained regarding the extractability of TCC and TPC in bee-pollen, when it was added to a pineapple juice-based beverage matrix and HPP-treated at different levels of pressure, time, and bee-pollen addition. Results showed an increase in bioactive compounds and antioxidant capacity, in particular when pressure and time close to $400 \mathrm{MPa}$ and 15 min were applied. Specifically, a treatment of $315 \mathrm{MPa}$ applied for 14.5 min combined with $8 \%(\mathrm{w} / \mathrm{v})$ bee-pollen inactivates at least $5 \log$ cycles of Salmonella and $Z$. rouxii and maximizes TCC, TPC content, and antioxidant activity. Finally, confocal images performed on untreated and treated beepollen grains showed a structural modification in the external layer of the grain, which may indicate that HPP treatment induced changes that favored the extractability of nutritional and bioactive compounds. Owing to their high bioactive compound content, HHP-treated products with inclusion of bee-pollen would be a promising and useful ingredient for formulating new functional foods. 


\section{Acknowledgments}

The authors thank the Colombian Administrative Department of Science, Technology and Innovation (COLCIENCIAS) and the Research Direction of Universidad Nacional de Colombia for their support, project AGL 2013-48993-C2-2-R and FEDER funds for resources.

\section{References}

Almeida-Muradian, L., Pamplona, L., Coimbra, S., \& Barth, O. (2005). Chemical composition and botanical evaluation of dried bee pollen pellets. Journal of Food Composition and Analysis, 18(1), 105-111.

Atkin, S., Barrier, S., Cui, Z., Fletcher, P., Mackenzie, G., Panel, V., ... Zhang, X. (2011). UV and visible light screening by individual sporopollenin exines derived from Lycopodium clavatum (club moss) and Ambrosia trifida (giant ragweed). Journal of Photochemistry and Photobiology B: Biology, 102, 209-217.

Barajas, J., Cortes-Rodriguez, M., \& Rodríguez-Sandoval, E. (2012). Effect of temperature on the drying process of bee pollen from two zones of Colombia. Journal of Food Process Engineering, 35(1), 134-148.

Barba, F., Criado, M. N., Belda-Galbis, C. M., Esteve, M. J., \& Rodrigo, D. (2014). Stevia rebaudiana Bertoni as a natural antioxidant/antimicrobial for high pressure processed fruit extract: Processing parameter optimization. Food Chemistry, 148, 261-267.

Barba, F., Esteve, M., \& Frigola, A. (2010). Ascorbic acid is the only bioactive that is better preserved by high hydrostatic pressure than by thermal treatment of a vegetable beverage. Journal of Agricultural and Food Chemistry, 58(18), 10070-10075.

Bogdanov, S. (2011). The Bee Pollen Book. Bee Product Science.

Butz, P., Fernandez-Garcia, A., Lindauer, R., Dieterich, S., Bognar, A., \& Tauscher, B. (2003) Influence of ultra high pressure processing on fruit and vegetable products. Journal of Food Engineering, 56, 233-236.

Campos, M., Bogdanov, S., Almeida-Muradian, L., Szczesna, T., Mancebo, Y., Frigerio, C., \& Ferreira, F. (2008). Pollen composition and standardisation of analytical methods. Journal of Apicultural Research and Bee World, 47(2), 156-163.

Carpes, S., Begnini, R., Alencar, S., \& Masson, M. (2007). Study of preparations of bee pollen extracts, antioxidant and antibacterial activity. Ciência E Agrotecnologia, 31(6), $1818-1825$

Castro, A., Rejon, J., Fendri, M., Jimenez-Quesada, M., Zafra, A., Jimenez-Lopez, M., \& Alche J. (2010). Taxonomical discrimination of pollen grains by using confocal laser scanning microscopy (CLSM) imaging of autofluorescence. Microscopy: Science, Technology.Applications and Education, 1(4), 607-613.

CFR (2012). Title 21: Food and drugs. FDA. Retrieved from http://www.accessdata.fda. gov/scripts/cdrh/cfdocs/cfcfr/CFRSearch.cfm?fr=120.24

Cook, S., Awmack, C., Murray, D., \& Williams, I. (2003). Are honey bees' foraging preferences affected by pollen amino acid composition? Ecological Entomology, 28(5), 622-627.

Fernández-García, E., Carvajal-Lérida, I., Jarén-Galán, M., Garrido-Fernández, J., PérezGálvez, A., \& Hornero-Méndez, D. (2012). Carotenoids bioavailability from foods: From plant pigments to efficient biological activities. Functional Foods and Nutraceuticals, 46(2), 438-450.

Franchi, G., Corti, G., \& Pompella, A. (1997). Microspectroscopic evaluation of digestibilty of pollen grains. Plant Foods for Human Nutrition, 50(2), 115-126.

Fuenmayor, C., Zuluaga, C., Diaz, C., Quicazán, M., Cosio, M. S., \& Mannino, S. (2014). Evaluation of the physicochemical and functional properties of Colombian bee pollen. Revista MVZ Córdoba, 19(1), 4003-4014.

Guardeño, L. M., Sanz, T., Fiszman, S. M., Quiles, A., \& Hernando, I. (2011). Microwave heating effect on rheology and microstructure of white sauces. Journal of Food Science, 76(8), E544-E552.

Hornero-Méndez, D., \& Mínguez-Mosquera, M. (2001). Rapid spectrophotometric determination of red and yellow isochromic carotenoid fractions in paprika and red pepper oleoresins. Journal of Agricultural and Food Chemistry, 49(8), 3584-3588.

Human, H., \& Nicolson, S. (2006). Nutritional content of fresh, bee-collected and stored pollen of Aloe geatheadii va. davyana (Asphodelaceae). Phytochemistry, 67. $1486-1492$.

Jung, L., Lee, S., Kim, S., \& Ahn, J. (2013). Effect of high hydrostatic pressure on the qualityrelated properties of carrot and spinach. Food Science and Biotechnology, 22(1). 189-195.
Kaškonienė, V., Ruočkuvienė, G., Kaškonas, P., Akuneca, I., \& Maruška, A. (2014). Chemometric analysis of bee pollen based on volatile and phenolic compound compositions and antioxidant properties. Food Analytical Methods, 8(5), 1150-1163.

Ketkar, S., Rathore, A., Lohidasan, S., Rao, L., Paradkar, A., \& Mahadik, K. (2014). Investigation of the nutraceutical potential of monofloral Indian mustard bee pollen. Journal of Integrative Medicine, 12(4), 379-389.

Leandro, M., Sychrova, H., Prista, C., \& Loureiro-Dias, M. C. (2011). The osmotolerant fructophilic yeast Zygosaccharomyces rouxii employs two plasma- membrane fructose uptake systems belonging to a new family of yeast sugar transporters. Microbiology, 157, 601-608

LeBlanc, B., Davis, O., Boue, S., DeLucca, A., \& Deeby, T. (2009). Antioxidant activity of Sonoran Desert bee pollen. Food Chemistry, 115(4), 1299-1305.

Markowicz, D., Barth, O., Rocha, C., Barbosa, I., Oliveira, P., Silva, E., \& Michelan, M. (2004). Fatty acid composition and palynological analysis of bee (Apis) pollen loads in the states of São Paulo and Minas Gerais, Brazil. Journal of Apicultural Research, 43(2), $35-39$.

McInerney, J., Seccafien, C., Stewart, C., \& Bird, A. (2007). Effects of high pressure processing on antioxidant activity, and total carotenoid content and availability, in vegetables. High Pressure Processing Special Issue Section, 8(4), 543-548.

Morais, M., Moreira, L., Feás, X., \& Estevinho, L. (2011). Honeybee-collected pollen from five Portuguese natural parks: Palynological origin, phenolic content, antioxidant properties and antimicrobial activity. Food and Chemical Toxicology, 49(5), 1096-1101.

Patras, A., Brunton, N., Da Pieve, S., \& Butler, F. (2009). Impact of high pressure processing on total antioxidant activity, phenolic, ascorbic acid, anthocyanin content and colour of strawberry and blackberry purées. Innovative Food Science \& Emerging Technologies, 10(3), 308-313.

Pinto, B., Caciagli, F., Riccio, E., Reali, D., Šarić, A., Balog, T., \& Scarpato, R. (2010). Antiestrogenic and antigenotoxic activity of bee pollen from Cystus incanus and Salix alba as evaluated by the yeast estrogen screen and the micronucleus assay in human lymphocytes. European Journal of Medicinal Chemistry, 45(9), 4122-4128.

Rastogi, N. K., Raghavarao, K. S. M. S., Balasubramaniam, V. M., Niranjan, K., \& Knorr, D. (2007). Opportunities and challenges in high pressure processing of foods. Critical Reviews in Food Science and Nutrition, 47(1), 69-112.

Roshchina, V., Melnikova, E., \& Kovaleva, L. (2010). Changes in fluorescence during development of the male gametophyte. Russian Journal of Plant Physiology, 44, 45-53.

Rowley, J., \& Skvarla, J. (2000). The elasticity of the exine. Grana, 39, 1-7.

Saucedo-Reyes, D., Marco-Celdrán, A., Pina-Pérez, M., Rodrigo, D., \& Martínez-López, A. (2009). Modeling survival of high hydrostatic pressure treated stationary- and exponential-phase Listeria innocua cells. Innovative Food Science \& Emerging Technologies, 10(2), 135-141.

Schulte, F., Mäder, J., Kroh, L., Panne, U., \& Kneipp, J. (2009). Characterization of pollen carotenoids with in situ and high-performance thin layer chromatography supported resonant Raman spectroscopy. Analytical Chemistry, 81, 8426-8433.

Serra-Bonvehí, J., Soliva-Torrentó, M., \& Centelles-Lorente, E. (2001). Evaluation of polyphenolic and flavonoid compounds in honeybee-collected pollen produced in Spain. Journal of Agricultural and Food Chemistry, 49(4), 1848-1853.

Singleton, V., Orthofer, R., \& Lamuela-Raventos, R. (1999). Analysis of total phenols and other oxidation substrates and antioxidants by means of Folin-Ciocalteu reagent. Methods in Enzymology, 299, 152-178.

Somerville, D., \& Nicol, H. (2002). Mineral content of honeybee-collected pollen from southern New South Wales. Australian Journal of Experimental Agriculture, 42(8), 1131-1136.

Souverein, O., Vries, J., Freese, R., Watzl, B., Bub, A., Miller, E., III, \& Boshuizen, H. (2015). Prediction of fruit and vegetable intake from biomarkers using individual participant data of diet-controlled intervention studies. British Journal of Nutrition, 113(9), $1396-1409$.

Thomasson, M., Baldwin, D., Diego-Taboada, A., Atkin, S., Mackenzie, G., \& Wadhawan, J. (2010). Electrochemistry and charge transport in sporopollenin particle arrays. Electrochemistry Communications, 12, 1428-1431.

Ulusoy, E., \& Kolayli, S. (2013). Phenolic composition and antioxidant properties of Anzer bee pollen. Journal of Food Biochemistry, 38(1), 73-82.

Vázquez-Gutiérrez, J. L., Plaza, L., Hernando, I., Sánchez-Moreno, C., Quiles, A., De Ancos, B., \& Cano, M. (2013). Changes in the structure and antioxidant properties of onions by high pressure treatment. Food E' Function, 4, 586-591. 